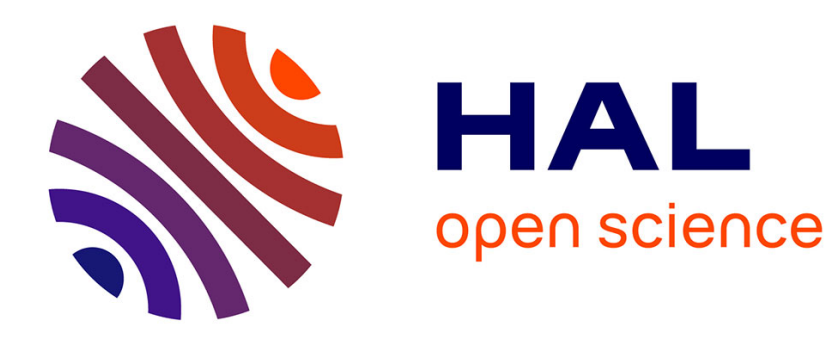

\title{
Blue-green solid state upconversion lasers
}

\author{
R. Macfarlane
}

\section{To cite this version:}

R. Macfarlane. Blue-green solid state upconversion lasers. Journal de Physique IV Proceedings, 1994, 04 (C4), pp.C4-289-C4-292. 10.1051/jp4:1994471 . jpa-00252734

\section{HAL Id: jpa-00252734 https://hal.science/jpa-00252734}

Submitted on 1 Jan 1994

HAL is a multi-disciplinary open access archive for the deposit and dissemination of scientific research documents, whether they are published or not. The documents may come from teaching and research institutions in France or abroad, or from public or private research centers.
L'archive ouverte pluridisciplinaire HAL, est destinée au dépôt et à la diffusion de documents scientifiques de niveau recherche, publiés ou non, émanant des établissements d'enseignement et de recherche français ou étrangers, des laboratoires publics ou privés. 


\title{
Blue-green solid state upconversion lasers
}

\author{
R.M. MACFARLANE
}

IBM Almaden Research Laboratory, San Jose, CA 95120-6099, U.S.A.

\begin{abstract}
We review the progress which has been made in the last several years on the development of upconversion lasers operating in the blue-green spectral region in terms of the nonlinear pumping mechanisms involved. Both single crystal and glass fiber systems are discussed.
\end{abstract}

Upconversion lasers use a nonlinear pumping scheme to excite a high lying electronic state which then produces laser emission. 1,2 In a true upconversion laser this emission has a higher frequency than that of the pump. The main goal is to produce blue or green $\mathrm{cw}$ laser light using near infrared pump light from semiconductor diode lasers. It is thus an alternative approach to that of frequency doubling and mixing of diode laser and Nd:YAG radiation which has recently enjoyed much success. ${ }^{3}$. $\Lambda$ ll of the bulk crystal upconversion lasers demonstrated so far use trivalent rare-earth ions doped at a level of $\sim 1 \%$ into transparent insulator hosts, usually fuorides. Rare-earth ions are particularly appropriate for upconversion lasers because they have numerous long lived metastable levels which store population during the upconversion process. Fluorides are chosen as host materials over oxides since the maximum phonon frequencies are lower, giving higher fluorescence quantum yields from the high lying excited states used in upconversion lasers. Crystal systems are very compact, typical gain media are $\sim 1 \mathrm{~mm}$ long, and have high peak cross sections, but most operate at reduced temperatures except in the less interesting pulsed mode. On the other hand, fluoride optical fibers, in particular ZBL $\Lambda N$ doped with $\sim 0.1 \%$ of trivalent rare-earths usually show room temperature operation. Fibers have the advantages of good confinement of the pump light giving efficient nonlinear excitation over a long gain medium and low doping levels which minimize thermal problems. Tables $1 \mathrm{a}$ and $1 \mathrm{~b}$ summarize the reports of blue/green crystalline and fiber upconversion lasers. The most interesting lasers are $\mathrm{cW}$ pumped, but the output of some consists of a train of pulses apparently due to undamped relaxation oscillations. The original references should be consulted for details of output and pump powers which vary widely but are generally in the range of ten and hundreds of $\mathrm{mW}$ respectively. Overall efficiencies vary from $<1 \%$ to $>25 \%$. I iber lasers are the most efficient so far, the best example being Tm:ZBI $\triangle \mathrm{N}^{23}$ which had an output of $55 \mathrm{~mW}$ for $190 \mathrm{~mW}$ of pump.

There are three principal mechanisms for upconversion excitation and all have been used as pumping schenies for lasers (see Table 1). They are: two-step absorption (2-st), (ii) energy transfer upconversion (ET) and (iii) avalanche absorption ( $\Lambda$ val.). Examples of upconversion lasers using each of these pumping mechanisms will be given. The use of a number of different real intermediate states makes the physics of upconversion lasers complicated but the devices themselves can be very simple monolithic cavities with mirrors applied directly to the crystal surfaces.

Two-step absorption is conceptually the simplest and most general pumping mechanism appropriate to almost any energy-level scheme. Here the system is pumped from its groundstate (1) to a metastable intermediate state (2), followed by a further excitation to the upper laser level (3) or to one which relaxes rapidly to this level. With modest pump powers of tens of $\mathrm{mW}$ focussed to $\sim 10 \mathrm{~kW} / \mathrm{cm}^{2}$ it is possible to transfer a substantial fraction of the population from the ground state to level (3). In crystals, the absorption bands of rare-earth ions are narrow and two different laser frequencies are generally required to pump the two 
Table 1a: BLUE-GREEN UPCONVERSION LASERS (Crystals)

\begin{tabular}{|c|c|c|c|c|c|c|}
\hline $\begin{array}{l}\text { Material } \\
\text { ton:Host }\end{array}$ & Transition & $\begin{array}{l}\text { Laser } \\
\lambda(\mathrm{nm})\end{array}$ & Mechanism & $\begin{array}{l}\text { Pump } \\
\lambda(\mathrm{nm})\end{array}$ & $T_{\max }(K)$ & Ref. \\
\hline $\mathrm{Nd}: \mathrm{LaF}_{3}$ & ${ }^{4} \mathrm{D}_{3 / 2} \rightarrow{ }^{4} \mathrm{I}_{11 / 2}$ & 380.1 & 2-st & $788+591$ & 90 & 4 \\
\hline $\mathrm{Nd}: Y \mathrm{LiF}_{4}$ & ${ }^{2} \mathrm{P}_{3 / 2} \rightarrow{ }^{4} \mathrm{I}_{11 / 2}$ & 413.0 & Aval. & 603.6 & 20 & 5 \\
\hline $\mathrm{Ho:Ba}(Y, Y b) F_{8}$ & ${ }^{5} S_{2} \rightarrow{ }^{5} I_{8}$ & 551.5 & ET & IR flashlamp & 77 & 1 \\
\hline $\mathrm{Er}: \mathrm{YAlO}_{3}$ & ${ }^{4} S_{3 / 2} \rightarrow 4_{15 / 2}$ & 549.6 & 2-st & $792+840$ & 77 & 6 \\
\hline Er:YLiF 4 & ${ }^{4} S_{3 / 2} \rightarrow{ }^{4} I_{15 / 2}$ & 551.1 & ET & $\begin{array}{c}797,969 \\
\sim 800 \text { (diode) } \\
1.50 \mu\end{array}$ & $\begin{array}{l}90 \\
90 \\
70\end{array}$ & $\begin{array}{c}7 \\
8,9 \\
10,11\end{array}$ \\
\hline $\mathrm{Er}_{\mathrm{Y}} \mathrm{LLiF}_{4}$ & $\begin{array}{l}\left.{ }^{2} \mathrm{H}_{9 / 2} \rightarrow{ }^{4}\right|_{13 / 2} \\
{ }^{2} P_{3 / 2} \rightarrow{ }^{4} I_{13 / 2}\end{array}$ & $\begin{array}{l}560.6 \\
469.7\end{array}$ & $\begin{array}{l}\text { ET } \\
\text { ET }\end{array}$ & $\begin{array}{c}967 \\
1.50 \mu\end{array}$ & $\begin{array}{l}35 \\
40\end{array}$ & $\begin{array}{l}12 \\
10\end{array}$ \\
\hline $\mathrm{Er}: \mathrm{BaY}_{2} \mathrm{~F}_{8}$ & $\begin{array}{l}\left.{ }^{4} S_{3 / 2} \rightarrow{ }^{4}\right|_{15 / 2} \\
{ }^{2} P_{3 / 2} \rightarrow{ }^{4} l_{13 / 2}\end{array}$ & $\begin{array}{l}551.7 \\
470.3\end{array}$ & $\begin{array}{l}\text { ET } \\
\text { ET }\end{array}$ & $\begin{array}{l}\sim 790, \sim 970 \\
\sim 790, \sim 970\end{array}$ & 30 & 13 \\
\hline $\mathrm{Er} \mathrm{YLiF}{ }_{4}$ & ${ }^{4} S_{3 / 2} \rightarrow{ }^{4} 1_{15 / 2}$ & 551 & 2-st & 810 (pulsed) & 300 & 14 \\
\hline Er: $\mathrm{KYF}_{4}$ & ${ }^{2} \mathrm{H}_{\mathrm{g} / 2} \rightarrow{ }^{4} \mathrm{I}_{13 / 2}$ & 561 & 2-st & 812(pulsed) & 300 & 14 \\
\hline Tm:YLiF 4 & ${ }^{1} \mathrm{D}_{2} \rightarrow{ }^{3} \mathrm{~F}_{4}$ & 453 & 2-st & $\begin{array}{c}781+648 \\
\text { (pulsed) }\end{array}$ & 300 & 15 \\
\hline Tm:YLiF 4 & $\begin{array}{l}{ }^{1} \mathrm{G}_{4} \rightarrow{ }^{3} \mathrm{H}_{6} \\
{ }^{1} \mathrm{D}_{2} \rightarrow{ }^{3} \mathrm{~F}_{4}\end{array}$ & $\begin{array}{l}483.0 \\
450.2\end{array}$ & $\begin{array}{l}\text { Aval. } \\
\text { 2-st }\end{array}$ & $\begin{array}{c}648 \\
784+648\end{array}$ & 160 & 16 \\
\hline$T m: Y A G$ & ${ }^{1} \mathrm{G}_{4} \rightarrow{ }^{3} \mathrm{H}_{8}$ & 486.2 & 2-st & $785+638$ & 30 & 17 \\
\hline$T m: B a(Y, Y b) F_{8}$ & ${ }^{1} \mathrm{D}_{2} \rightarrow{ }^{3} \mathrm{H}_{8},{ }^{3} \mathrm{H}_{5}$ & 455,510 & ET & 960 & 90,200 & 18 \\
\hline
\end{tabular}

Table 1b: BLUE-GREEN UPCONVERSION LASERS (Fibers)

\begin{tabular}{|c|c|c|c|c|c|c|}
\hline $\begin{array}{l}\text { Material } \\
\text { lon:Host }\end{array}$ & Transition & $\begin{array}{l}\text { Laser } \\
\lambda(\mathrm{nm})\end{array}$ & Mechanism & $\begin{array}{l}\text { Pump } \\
\lambda(\mathrm{nm})\end{array}$ & $T_{\max }(K)$ & Ref. \\
\hline Pr:ZBLAN & $\begin{array}{l}{ }^{3} \mathrm{P}_{0} \rightarrow{ }^{3} \mathrm{H}_{4} \\
{ }^{3} \mathrm{P}_{1} \rightarrow{ }^{3} \mathrm{H}_{5}\end{array}$ & $\begin{array}{l}491 \\
520\end{array}$ & $\begin{array}{l}\text { 2-st } \\
2 \text {-st }\end{array}$ & $\begin{array}{r}1010 \\
+835\end{array}$ & 300 & 19 \\
\hline Ho:ZBLAN & ${ }^{5} S_{2} \rightarrow{ }^{5} /_{8}$ & $540-553$ & 2-st & 647.1 & 300 & 20 \\
\hline Er:ZBLAN & $\left.{ }^{4} S_{3 / 2} \rightarrow{ }^{4}\right|_{15 / 2}$ & 546 & 2-st & 801 & 300 & 21 \\
\hline Tm:ZBLAN & $\begin{array}{l}{ }^{1} \mathrm{G}_{4} \rightarrow{ }^{3} \mathrm{H}_{6} \\
{ }^{1} \mathrm{D}_{2} \rightarrow{ }^{3} \mathrm{~F}_{4}\end{array}$ & $\begin{array}{l}480 \\
455\end{array}$ & $\begin{array}{l}2 \text {-st } \\
2 \text {-st }\end{array}$ & $\begin{array}{r}647.1 \\
+676.4\end{array}$ & 77 & 22 \\
\hline Tm:ZBLAN & ${ }^{1} \mathrm{G}_{4} \rightarrow{ }^{3} \mathrm{H}_{6}$ & 480 & 2-st & $\begin{array}{r}1112 \\
+1116 \\
+1123\end{array}$ & 300 & 23 \\
\hline Tm:ZBLAN & ${ }^{1} \mathrm{G}_{4} \rightarrow{ }^{3} \mathrm{H}_{6}$ & 480 & 2-st & 1111 & 300 & 24 \\
\hline
\end{tabular}


resonances at $\omega_{12}$ and $\omega_{23}$. In glasses however, the bands are broader and a single frequency is usually sufficient. Although the first example of an upconversion laser pumped by two-step absorption was a crystalline system ${ }^{6} \mathrm{Er}^{3}: \mathrm{Y}^{\prime} \mathrm{AlO} \mathrm{O}_{3}$, and several other examples are given in Table 1a, this mechanism is particularly appropriate to the case of optical fibers where, apart from the case of energy transfer from $\mathrm{Yb}$, neither of the other two mechanisms has been used. This is because, at the low concentration of the active ion which is used in conjunction with the long gain medium $(\sim 1 \mathrm{~m})$, ion-ion coupling is too weak to produce significant energy. transfer. Two-step absorption is also the mechanism often used in pulse pumping where the excitation time does not allow efficient population of long lived metastable levels.

Most of the crystal upconversion laser systems use the second mechanism - energy transfer pumping. This is either a cross-relaxation between two excited ions (the 'APTE' process of $\mathrm{Auze}^{25}$ ) or a sequential or cooperative transfer process in which one or more excited ions (usually $\mathrm{Yb}^{3+}$ ) give their energy to the active center. The advantage of these pumping schemes, which become effective at a doping level of $\sim 1 \%$, is that only a single pump laser is required and the system provides its own nonlinearity via ion-ion coupling. The most important example to date is $\mathrm{Er} \mathrm{YLiF}_{4}$ where excitation at $797 \mathrm{~nm}$ into the ${ }^{4} \mathrm{I}_{9 / 2}$ level, or around $970 \mathrm{~nm}$ into ${ }^{4} \mathrm{I}_{11 / 2}$, populates the metastable ${ }^{4} \mathrm{I}_{11 / 2}$ level. Two ions in this level cross-relax to efficiently produce ${ }^{4} S_{3 / 2}$ followed by laser action to the ${ }^{4} \mathbf{I}_{15 / 2}$ ground manifold. A surprising finding was the efficiency of multiple upconversion steps. In the case of pumping at $1.5 \mu$ into ${ }^{4} \mathrm{I}_{13 / 2}$ a sequence of upconversion steps populates the ${ }^{2} \mathrm{P}_{3 / 2}$.level which has an energy five times higher than that of the pump light. ${ }^{9}$ Iaser action occurs from this level to ${ }^{4} 1_{11 / 2}$ at $467.9 \mathrm{~nm}$. One can expect even higher laser frequencies based on this kind of pumping scheme, although at very high frequencies the probability of excited state absorption losses increases. This highlights another reason for the choice of fluoride hosts which show good transparency in the ultra-violet. Note that, because of the population of real, metastable intermediate levels in upconversion pumping these multiple steps occur with almost the same efficiency as for one or two steps. This is in strong contrast to the case of harmonic generation.

The third mechanism, that of avalanche absorption requires only one pump source resonant with an excited state transition. ${ }^{26-28}$ At this pump frequency there is a very small absorption from the ground state which populates a metastable level which then absorbs a resonant pump photon. The resulting excited-state ion cross relaxes with a ground state ion, pumping it to the first metastable level and itself relaxing to this level. Thus two excited ions are produced for each pump photon absorbed and an avalanche absorption can result. This is a surprisingly efficient pump mechanism in which the absorption of pump light changes with time, usually changing from less than $1 \%$ to more than $50 \%$ in a time of $10^{\prime} \mathrm{s}$ to $100^{\prime} \mathrm{s}$ of msecs. The first laser pumped in this way was $\mathrm{Nd}: \mathrm{YLiF}_{4}{ }^{5}$ and $\mathrm{Tm}$ systems are particularly effective (see Table la). Because of the long delay in the onset of absorption from the pump, this mechanism is only applicable to cw or very long pulse excitation.

In this brief report I have tried to indicate the wide diversity of upconversion lasers that have been demonstrated. Because of the strong dependence of many of the laser parameters on the energy level structure of the active ion, each material presents different opportunities and problems. Not all of these lasers listed in Table 1 are important, but most illustrate important aspects of the nonlinear pumping mechanisms which lie at the heart of upconversion. $\Lambda$ mong the highlights of the field are the efficient room temperature operation of nuoride fiber lasers, the possibility of multiplc excitation steps to produce frequencies much higher than that of the pump and the variety of upconversion mechanisms that lead to laser action. $\Lambda$ natural and promising evolution of the field is toward planar waveguide lasers which combine some of the advantages of the high degree of confinement of fibers with high peak cross-sections of crystals. Although several laboratories have programs in the areas of rare-earth doped epitaxial films ${ }^{29}$ and waveguide lasers ${ }^{30}$ with obvious applications to upconversion, no waveguide upconversion lasers have been operated and with rare exceptions ${ }^{30}$ there are very few measurements of a very important parameter: waveguide loss. The field is relatively young and many materials await discovery. It seems likely that the unique capabilities of upconversion lasers will result in practical devices that are competitive with other methods of generating blue and green light from IR and near IR pump sources. 


\section{REFERENCES}

1. L. F. Johnson and H. J. Guggenheim, Appl. Phys. Lett. 19, 44 (1971).

2. W. Lenth and R. M. Macfarlane, Opt. Phot. News 3, \#3, 8 (1992).

3. W. Lenth, W. J. Kozlovsky, R. M.Macfarlane and W. P. Risk, SPIE, 1219, 21 (1990); W. J. Kozlovsky, W. Lenth, E. E. Latta, A. Moser and G. L. Bona, Appl. Phys. Lett. 56, 2291 (1990); W. P. Risk and W. J. Kozlovsky, Opt. Lett., 17, 707 (1992); P. N. Kean, R. W. Standley and G. J. Dixon, Appl. Phys. Lett. 63, 302 (1993).

4. R. M. Macfarlane, F. Tong, $\Lambda$. J. Silversmith and W. Lenth, Appl. Phys. Lett. 52, 1300 $(1988)$.

5. R. M. Macfarlane, $\Lambda$. J. Silversmith, F. Tong and W. Lenth, Proc. Int. Conf. on Laser Science and laser Materials, Shanghai, July 25-27, 1988, eds. Z. J. Wang and Z. M. Zhang, World Scientific, Singapore, 1989 p.24.

6. A. J. Silversmith, W. Lenth and R. M. Macfarlane, J. Opt. Soc. Am., A3, P128 (1986); A. J. Silversmith, W. Lenth and R. M. Macfarlane, Appl. Phys. Lett. , 51, 1977 (1987).

7. W. Lenth, A. J. Silversmith and R. M. Macfarlane, Adv. in Laser Science III, Eds. A. C. Tam, J. L. Gole and W. C. Stwalley, Proc. AIP, 172, 8 (1987); R. A. McFarlane, Appl. Phys. Lett., 54, 2301 (1989); R. A. McFarlane, Opt. Lett., 16, 1397 (1991).

8. T. Hebert, W. P. Risk, R. M. Macfarlane and W. Lenth, Advanced Solid State Lasers, Vol. 6 Eds. H. P. Jenssen and G. Dubé, Opt. Soc. Am., p.379, Washington DC (1990);

9. R. R. Stephens and R. A. McFarlane. Opt. Lett. , 18, 34 (1993).

10. R. M. Macfarlane, E. A. Whittaker and W. Lenth, Electron. Lett. , 28, 2136 (1992).

11. P. Xie and S. C. Rand, Opt. Lett. , 17, 1198 (1992).

12. T. Hebert, R. Wannemacher, W. Lenth and R. M. Macfarlane, Appl. Phys. Let1. 57, 1727 (1990).

13. R. A. McFarlane Proc. Adv. Solid State Lasers, 13, Opt. Soc. Am., Washington, DC (1992) p. 275.

14. R. Brede, E. Heumann, J. Koetke, T. Danger, G. Huber and B. Chai, Appl. Phys. Lett. 63, 2030 (1993).

15. D. C. Nguyen, G. E. Faulkner, M. E. Weber and M. Dulick, SPIE , 1223, 54 (1990).

16. T. Hebert, R. Wannemacher, W. Lenth and R. M. Macfarlane, Appl. Phys. Lett., 57, $1727(1990)$.

17. B. P. Scott, F. Zhao, R. S. F. Chang and N. Djeu, Opt. Lett. 18, 113 (1993).

18. R. J. Thrash and L. F. Johnson OSA Ann. Mtg., Toronto (1992), paper MJ1; R. J. Thrash, R. A. Raddatz and L. F. Johnson, ILS-IX, Toronto (1993), paper MOO-3; R. J. Thrash priv, commun.

19. R. G. Smart, D. C. I Ianna, A. C. Tropper, S. T. Davey, S. F. Carter, and D. Szebesta, Electron. Lett. , 27, 1307 (1991).

20. J. Y. Allain, M. Monerie, and H. Poignant, Electron. Lett., 26, 261 (1990).

21. T. J. Whitley, C. A. Millar, R. Wyatt, M. C. Brierley and D. Szebesta, Electron. Lett. , 27, 1785 (1991).

22. J. Y. Allain, M. Monerie and H. Poignant, Electron. Lett., 26, 166 (1990).

23. S. G. Grubb, K. W. Bennett, R. S. Cannon and W. F. IIumer, Eleciron. Lett., 28, 124 $(1992)$.

24. C. J. Mackechnic, W. L. Barnes, D. C. IIanna and J. I. Townsend, Electron. Lett. , $29,52(1993)$.

25. F, Auzel, C.R. Arad. Sci. (Paris), 262, 1016 (1966).

26. J. S. Chivian, W. E. Case and D. D. Eden, Appl. Phys. Lett., 35, 124 (1979) A. W. Kueny, W. Li. Case and M. E. Koch, J. Opt. Soc. Am., B6, 639 (1989); M. E. Koch, $\Lambda$. W. Kueny and W. E. Case, Appl. Phys. Leth., 56, 1083 (1990).

27. W. Jenth and R. M. Macfarlane, J. Lumin., 45, 346 (1990).

28. M. F. Joubert, S. Guy and B. Jacquier, Phys. Rev., B48, 10031 (1993).

29. L. E. Bausa, C. Fontaine, E. Daran and A. Munoz-Yague J. Appl. Phys., 72, 499 (1992); M. Lui, R. $\Lambda$. Mcl arlane, D. Yap and D. Lederman, Electron. Lett. , 29, 172 (1993).

30. I Chartier, B. Ferrand, D. Pelenc, S. J. Field, D. C. Hanna, A. C. Large, D. P. Shepherd and A. C. Tropper, Opt. Lett., 17, 810 (1992). 